\title{
What the contract does not say... A current analysis of what's missing in clinical trial agreements
}

G Agar, BA (Hons) Psychol, BA (Hons) Brand Leadership, BSc Human Physiol, Genetics Psychol;

L J Burgess, PhD Chem Pathol, MSc Clin Res, MB ChB, MMed, Postgrad Dip Internat Res Ethics

TREAD Research CC, Cardiology Unit, Department of Internal Medicine, Tygerberg Hospital and Stellenbosch University

Corresponding author: L J Burgess (lesley@treadresearch.com)

\begin{abstract}
Introduction. Increasing numbers of litigation cases in clinical research highlight the need for definitive and transparent clinical trial agreements (CTAs). The requirements set by the Association for the Accreditation of Human Research Protection Programs (AAHRPP) are an attempt to minimise miscommunication between sponsor and site, and promote human research protection. These requirements include: (i) the obligation of the sponsor and/or its representative to communicate study results; (ii) the obligation of the sponsor and/or its representative to promptly report any findings that could affect the participants' safety and/or influence study conduct; and (iii) the sponsor's liability for the cost of medical care in the event of a research-related injury.

Objective. To analyse 40 CTAs as to which of the AAHRPP requirements they met.

Methodology. Forty consecutive CTAs signed by our institution, with 15 different research sponsors, were analysed and tracked as to which AAHRPP criteria they met.

Results. No CTAs complied with all the AAHRPP requirements. Notably, 17.5\% stipulated that the sponsor would communicate study results, but none stipulated that it would directly inform the site of these results; $35 \%$ stated that the sponsor would be responsible for reporting any findings/additional information that might affect participants' safety and/or influence the conduct of the study; and $40 \%$ explicitly stipulated that the sponsor was obliged to pay for the cost of patients' medical care in the event of a research-related injury.

Conclusions. The AAHRPP requirements are an attempt to minimise miscommunication between sponsor and site, yet most CTAs fail to stipulate what should be fundamental requirements of every contract.
\end{abstract}

S Afr J Bioethics Law 2018;11(1):20-23. DOI:10.7196/SAJBL.2018.v11i1.603

There has been an increase in clinical trial litigation in the last few years both in South Africa (SA) and abroad, with plaintiffs suing various role players - including research sponsors, institutions and investigators. ${ }^{[1-4]}$ This has highlighted the need for a legally effective clinical trial agreement (CTA) to be concluded between the various parties prior to the commencement of a clinical trial. The CTA should describe and acknowledge responsibilities, terms of collaboration, requirements for payment and reimbursement, publication and intellectual property terms, indemnification and/or insurance, subject injury coverage, guidelines for dispute resolution, grounds for termination of contract and the possibility of amending contract terms in the future. ${ }^{[1]}$ In addition, the CTA should protect the participant, sponsor and investigator.

In recent years, global human research protection programmes (HRPPs) have put steps in place to minimise contract ambiguity and cause for litigation. One such example is the Association for the Accreditation of Human Research Protection Programs (AAHRPP), which promotes high-quality, ethically sound research through an accreditation process that helps organisations worldwide strengthen their HRPPs. ${ }^{[5]}$

An independent, non-profit accrediting body, AAHRPP uses a voluntary, peer-driven, educational model to ensure that HRPPs meet rigorous standards for quality and protection. To earn accreditation, organisations must provide tangible evidence - through policies, procedures, and practices - of their commitment to scientifically and ethically sound research, and to continuous improvement. ${ }^{\left[{ }^{[6]}\right.}$

As the 'gold seal', AAHRPP accreditation offers assurances - to research participants, researchers, sponsors, government regulators and the public - that an HRPP is focused first and foremost on excellence. ${ }^{[6]}$

In accordance with AAHRPP, the following statements need to be included in the CTA:

'(i) The sponsor and/or its representative will be responsible for costs of medical care [if] a participant suffers a research-related injury.

(ii) The sponsor and/or its representative is/are obligated to promptly report to the Organisation any findings that could:

a. affect the safety of participants

b. influence the conduct of the study.

(iii) The sponsor and/or its representative is/are obligated to promptly send the organisation all data and safety monitoring plans and reports.

(iv) The sponsor and/or its representative is/are obligated to promptly communicate findings from any research study, even after its closure, when those findings could directly affect the safety of participants. ${ }^{[5]}$

In this study, we aimed to analyse whether CTAs from various sponsors met these minimum requirements. 


\section{Methodology}

Forty consecutive CTAs that were signed by our institution, with 15 different SA-based research sponsors, were analysed as to which AAHRPP criteria they met. All studies analysed were cardiovascular research studies. These 40 CTAs were signed between May 2013 and February 2016. The analysis took place during March - May 2016.

The CTAs were listed in a table format, and individually tracked by a single rater as to which of the following criteria they met, by including:

- a statement discussing the obligation of the sponsor to communicate study results

- a statement discussing the obligation of the sponsor to report findings that may affect participant safety/influence study conduct

- a statement discussing the obligation of the sponsor to send data and safety-monitoring reports

- a statement that the sponsor and/or its representative will be responsible for costs of medical care if a participant were to suffer a research-related injury

- an insurance certificate

- indemnification of the research site

- a statement in the informed consent form that the Association of the British Pharmaceutical Industry (ABPI) compensation guidelines will be followed.

All 40 trials had been approved by the SA Medicines Control Council (MCC) and the Stellenbosch Health Research Ethics Committee (HREC). It should be noted that as per AAHRPP regulations, containing any of the above requirements in the informed consent forms does not absolve the clinical trial agreement from also needing to include them (apart from the statement that ABPI guidelines would be followed). Also, stating that the trial will be carried out as per good clinical practice guidelines does not secondarily fulfil any of the above criteria.

This study did not involve research participants, as it is an analysis of our own records, which are kept confidential. Therefore, ethics approval was not necessary.

\section{Results}

None of the CTAs demonstrated compliance with all the AAHRPP requirements. CTAs are becoming longer and more complex, yet the onus remains on the clinical trial sites to comply with them ${ }^{[7]}$ - more obligations are being assigned to sites, while sponsor obligations are overlooked, as demonstrated below. This is especially prevalent in the reporting of safety issues and the communication of study results, as seen in Fig. 1.

Only $17.5 \%$ of contracts analysed in this study stipulated that the sponsor would communicate study results, and of these, none stipulated that it would directly inform the site of these results. They merely stated that the results would be released publically, meaning that the busy site would have to follow up themselves. Sponsors seem overly concerned with sites first obtaining permission to publish study results, and most fail to mention their own obligation to share study results.

Only $35 \%$ of contracts stated that the sponsor would be responsible for reporting any findings/additional information that may affect participant safety or influence the conduct of the study. And only $15 \%$ of contracts acknowledged the sponsor's responsibility to share data

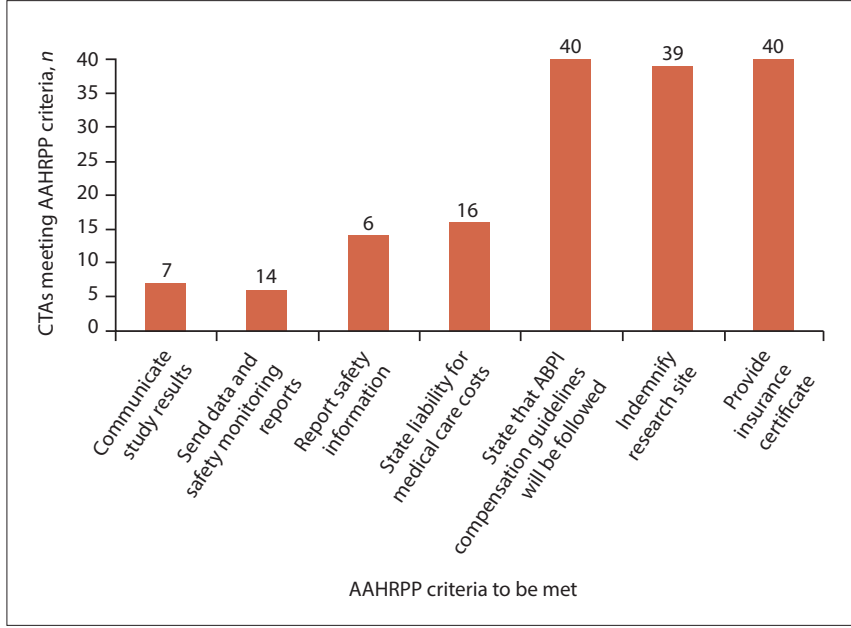

Fig. 1. Prevalence of each AAHRPP criterion in CTAs ( $\mathrm{N}=40)$. $($ AAHRPP $=$ Association for the Accreditation of Human Research Protection Programs; ABPI = Association of the British Pharmaceutical Industry; $C T A=$ clinical trial agreement.)

and safety monitoring reports with the site. Only $40 \%$ of clinical trial agreements explicitly stipulated that the sponsor was obliged to pay for the cost of the patients' medical care. An encouraging finding from the study is that $100 \%$ of contracts contained insurance certificates, and $97.5 \%$ contained statements covering indemnification of the research site. Additionally, every contract's corresponding informed consent form (ICF) contained a statement that ABPI compensation guidelines would be followed. Overall, out of the 280 criteria analysed $(7 \times 40$ CTAs), 162 were met, giving a general completion rate of $58.86 \%$

\section{Discussion \\ Sponsors' obligation to communicate study results with the study site}

Of the 40 CTAs reviewed, only $7(17.5 \%)$ of the contracts stated that the sponsor was obligated to communicate the study results. Furthermore, this was invariably an obligation to the sites and not to the actual trial participants themselves. ${ }^{[8]}$

These results are made more pertinent by the recent European Union (EU) regulations, which dictate that a lay language summary of study results must be made available to study participants, irrespective of the study outcome. ${ }^{[8]}$ The EU states that this summary must include:

- clinical trial identification

- name and contact details of the sponsor

- main objectives

- population of subjects (including eligibility criteria)

- investigational medicinal products used

- description of adverse events and frequency

- overall results of the clinical trial

- comments on the outcome of the clinical trial

- information as to whether follow-up clinical trials are foreseen

- information on where additional information can be found. ${ }^{[9]}$

Given that these EU regulations were implemented in 2016, it is concerning that such a low number of contracts made mention of this obligation. It is important to communicate study results to participants. For many, the stigma of clinical trial participants being 
seen as 'human guinea pigs' remains; therefore it is vital for the industry to be as transparent and trustworthy as possible, to move towards shifting public perception away from such myths. ${ }^{[10]}$ The 2015 Center for Information \& Study on Clinical Research Participation (CISCRP) Report on Participation Experiences ${ }^{[1]]}$ conducted a study in which approximately 12000 participants of clinical trials worldwide completed surveys pertaining to their experiences. Of these, $90 \%$ of participants want to know the results of their clinical trial, $91 \%$ had never heard back from the study staff or sponsor, and $68 \%$ would not participate in future trials if left uninformed. ${ }^{[11]}$ These results portray the considerable number of patients who are never informed about the results of their trial, and highlight the importance of keeping participants informed, as it is often mistakenly taken for granted that they 'are not interested.'

There is also the ethical obligation to communicate study results to participants, as it is fundamentally the 'right thing to do' and helps build patients' trust and satisfaction with their clinical trials. ${ }^{[8]}$ Many participants finish their trials and remain unaware of the study results indefinitely, as they are simply not communicated to them.

\section{Sponsors' obligation to share current study safety data with the research site}

Only $15 \%$ of CTAs stated that the sponsor was obligated to send data and safety monitoring reports to the site. Furthermore, only $35 \%$ of these CTAs stated that the sponsor was obligated to report findings that may affect participants' safety and/or influence study conduct. This may have a negative effect on sites' ability to communicate results to participants and, more importantly, their ability to protect the participant legally, ethically, and physically.

While it is true that sponsors, in the research site's own experience, do usually communicate this information through safety letters, weekly reports, etc., the lack of a legal obligation to do so can lead to intentionally hidden or misrepresented data being communicated. Sponsors may choose to do this in order to deceive investigators into carrying on with the study, and also to make the results 'look better' in order to have their product approved and bring it to shelves. While extremely unethical, these sorts of practices have occurred in the past, such as with the Vioxx fiasco. ${ }^{[12]}$

Vioxx (rofecoxib) was introduced in 1999 by Merck as an effective, safer alternative to non-steroidal anti-inflammatory drugs for treating osteoarthritis pain. ${ }^{[12]}$ The drug was found to raise the risk of developing cardiovascular disease, and eventually withdrawn from market. However, there is evidence that early suspicion of cardiovascular risk existed as well as deliberate obscuring of data in order to downplay these risks and promote the efficacy of the drug, in order to bring it to market. Since early development, some scientists at Merck were concerned that the drug may affect the cardiovascular system by altering the ratio of prostacyclin to thromboxane, which act in opposition, balancing blood flow and clotting. ${ }^{[12]}$ From internal emails there is evidence that Merck sought to soften academic authors' interpretation that the drug might lead to increased thrombus formation. Yet despite this knowledge, none of the early intervention studies were designed to evaluate the drug's cardiovascular risk. Instead, data were pooled and results circulated to promote the drug's safety to doctors through Merck's 'cardiovascular card,' a non-FDA (Food and Drug Administration)approved marketing tool. ${ }^{[12]}$
There is evidence of deliberate obscuring of data to downplay the cardiovascular risks. An interim analysis of the drug's VIGOR study changed the termination dates for cardiovascular event reporting in order to exclude three events of myocardial infarction. The termination date for gastrointestinal events remained the same, with results favouring the drug's effect on gastrointestinal events while understating the risk of cardiovascular events. ${ }^{[12]}$ The data were further concealed by Merck using naproxen (the comparator drug) as the intervention group for presenting the hazard of myocardial infarction, even though all other results were properly presented with rofecoxib as the comparator. By presenting the information in this manner, Merck argued that naproxen increased cardiovascular protection (despite no evidence of this), rather than Vioxx increasing cardiovascular risk. ${ }^{[12]}$ Merck has since voluntarily withdrawn Vioxx, but has upwards of 30000 legal claims from people who suffered cardiovascular events while taking the drug, which Merck denies liability for. ${ }^{[12]}$

The withholding of (or tampering with) safety data can have resonating repercussions for the participant, sponsor and, by extension, the site. It highlights the importance of transparency when conducting clinical research, and the need to communicate the safety data.

\section{Obligation to cover the costs of medical care}

Only $40 \%$ of the CTAs explicitly stated that the sponsor and/or its representative would be responsible for the cost of medical care if a participant were to suffer a research-related injury. The importance of this is highlighted by the fact that clinical trial sites have been exploited by patients and sponsors alike, owing to contracts not being explicit enough. A recent case that drew attention in the SA clinical trial industry was Venter v Roche Products (Pty) Limited and Others. In this case the Western Cape High Court had to adjudge whether the plaintiff, Mr Venter, was due additional compensation for non-medical costs such as pain and suffering, loss of income and general damages, even though Mr Venter had signed an ICF which expressly excluded such claims. ${ }^{[3]}$

This ICF stated that the sponsor would pay only for the cost of any trial-related medical treatment the participant may have undergone, and that any further claims for compensation would be determined using the ABPI compensation guidelines. Mr Venter suffered a research-related injury and hospitalisation, and it was as a result of this incident that the plaintiff claimed to have suffered damages. ${ }^{[3]}$

Upon review of the aforementioned ICF and the ABPI guidelines, it was determined that there was no legal obligation for compensation to be paid beyond the medical costs incurred. It must also be noted that the court took into consideration the fact that such studies and their corresponding documents undergo expert legal and ethical review by the MCC and research ethics committees before being approved. The court accepted that limiting compensation in this way was reasonable, as these regulatory committees had the legal authority to approve or not approve such research. ${ }^{[3]}$ Therefore, in light of the arguments above, the court dismissed the case. ${ }^{[3]}$

Many of the clinical trials in SA form part of multinational trials that take place at numerous sites across the world. The parent company sponsor for these trials is rarely South African, and as such, the original CTAs are drafted in countries with different health practices and laws to SA's. Contracts are amended to suit the trial country; however, 
sometimes the differences are not fully realised and implemented, and ambiguity and exclusion of necessary information can occur.

An example of this would be difference between SA and the USA with regard to remunerating health research participants. US contracts typically state that were a patient to suffer a research-related injury, they would pay above what healthcare covers, whereas in SA participant remuneration is determined using the aforementioned ABPI compensation guidelines. It is promising that $100 \%$ of the reviewed ICFs contained statements that ABPI guidelines would be followed.

Specific compensation guidelines are vital for cases such as the 2010 India incident. Of the 25 people who suffered trial-related deaths in India in 2010, only 5 of the families had been compensated an amount of INR1.5 - 3 lakh (approximately ZAR30 000 - 60000 at the time). ${ }^{[13]}$ The Drug Controller General of India summoned the nine pharmaceutical companies responsible to question them on the compensatory amount (determined by the companies' internal ethics committees), and ordered them to pay all compensation or risk any future trials being disallowed. As a direct reaction to this incident, in 2011, the Indian Council of Medical Research drafted official compensation guidelines for participants suffering research-related injuries in India. ${ }^{[13]}$

\section{Conclusion}

With the increasing number of litigation cases in clinical research, both locally and abroad, there is a growing need for definitive and transparent clinical trial agreements. ${ }^{[3,4]}$ Clearly defined roles for both sponsor and site would help to reduce ambiguity and confusion between the two. The AAHRPP requirements are an attempt to minimise miscommunication between sponsor and site, yet as this study shows, a worrying number of CTAs fail to stipulate what should be fundamental requirements of every contract.

Of the 40 CTAs reviewed, only $7(17.5 \%)$ of the contracts stated that the sponsor was obligated to communicate the study results. Furthermore, this was invariably an obligation to the sites, and not to the actual trial participants themselves. These results are made more pertinent by the EU regulations dictating that a lay language summary of study results must be published to study participants, irrespective of the study outcome. ${ }^{[9]}$ And as shown through the CISCRP study, patients do want to be informed about the results of their trials. ${ }^{[1]}$ Only $15 \%$ of CTAs stated that the sponsor was obligated to send data and safety-monitoring reports to the site. Furthermore, only $35 \%$ of these CTAs stated that the sponsor was obligated to report findings that may affect participant safety and/or influence study conduct. This may have a negative effect on sites' ability to communicate results to participants and, more importantly, their ability to protect the participant legally, ethically and physically. Only $40 \%$ of the CTAs explicitly stated that the sponsor and/or its representative would be responsible for the cost of medical care were a participant to suffer a research-related injury. The importance of this is highlighted by the fact that clinical trial sites have previously been exploited by patients and sponsors alike, as a result of insufficiently explicit contracts. ${ }^{[3]}$

Further research of this nature could be useful in addressing this study's limitations. For example, more clinical research sites could conduct similar studies, and multiple raters could be used to improve reliability.

Acknowledgements. None.

Author contributions. Equal contributions.

Funding. None.

Conflicts of interest. None.

1. The Ohio State University Center for Clinical \& Translational Science. Clinical Trial Agreement. Columbus: The Ohio State University, 2012. https://ccts.osu.edu/ education-and-training-programs/research-education-and-training-programs/ clinical-research-coordinator-resources/clinical-trial-agreement (accessed 25 March 2017).

2. Wilson R. The death of Jess Gelsinger: New evidence of the influence of money and prestige in human research. Am J Law Med 2010;36(2-3):295-325. https://doi. org/10.1177/009885881003600202

3. Strode A, Singh P. Compensation for research-related harm: The implications of Venter v Roche Products (Pty) Limited and Others for research ethics committees. S Afr Med J 2014;104(11):759-761. https://doi.org/10.7196/SAMJ.8596

4. Wadlund J. Heading off a clinical trial liability lawsuit. Appl Clin Trials 2003;12:50-53.

5. Association for the Accreditation of Human Research Protection Programs. Domain I: Organization. Washington, DC: AAHRPP, 2012. http://aahrpp.org/ apply/web-document-library/domain-i-organization (accessed 8 February 2017).

6. Association for the Accreditation of Human Research Protection Programs. Our Mission, Vision, and Values. Washington, DC: AAHRPP, 2017. http://www.aahrpp. org/learn/about-aahrpp/our-mission (accessed 14 November 2017).

7. Burgess $L J$, Sulzer NU. The growing disparity between clinical trial complexity and investigator compensation. Cardiovasc J Afr 2010;21(5):249-250. https:// www.ncbi.nlm.nih.gov/pmc/articles/PMC3721298/ (accessed 15 Nov 2017).

8. Bierer BE, Li R, Myers L, Collyar D. Practical implementation of return of results to patients. Cambridge, MA: Multi-Regional Clinical Trials Center, Harvard University, 19 February 2017.

9. European Parliament, Council of the European Union. EUR-Lex. http://eur-lex europa.eu/legal-content/EN/TXT/?uri=uriserv:OJ.L_.2014.158.01.0001.01.ENG (accessed 2 June 2017).

10. Memorial Sloan Kettering Cancer Center. Despite Pressing Need, Survey Finds Most Americans Unlikely to Enroll in Clinical Trials. New York: Memorial Sloan Kettering Cancer Center, 2016. https://www.mskcc.org/press-releases/despite-pressing-needsurvey-finds-most-americans-unlikely-enroll-clinical-trials (accessed 15 Nov 2017).

11. Center for Information \& Study on Clinical Research Participation. Report on Participation Experiences. Boston: CISCRP, 2015. https://www. ciscrp.org/download/2015-perceptions-insights-study-participantexperiences/?wpdmdl=5742 (accessed 2 June 2017).

12. Krumholz HM, Ross JS, Presler AH, Egilman DS. What have we learnt from Vioxx? BMJ 2007;334(7585):120-123. https://doi.org/10.1136\%2Fbmj.39024.487720.68

13. Sinhal K. Clinical trials claimed 25 lives in 2010 , only 5 paid compensation. Mumbai: The Times of India, 2011. http://timesofindia.indiatimes.com/india/Clinical-trialsclaimed-25-lives-in-2010-only-5-paid-compensation/articleshow/8740602.cms (accessed 2 June 2017).

14. Prescriptions Medicines Code of Practise Authority. Introduction. London: PMCPA, 2016 http://www.pmcpa.org.uk/thecode/InteractiveCode2016/Pages/ Introduction.aspx\# (accessed 19 March 2017)

15. Anderlik M, Elster N. Currents in contemporary ethics. J Law Med Ethics 2001:20(1):220-228. https://doi.org/10.1111\%2Fj.1748-720x.2001.tb00710.x

16. Steinbrook R. Protecting research subjects - the crisis at John Hopkins. New Engl J Med 2002;346(9):716-720. https://doi.org/10.1056\%2Fne jm200202283460924

Accepted 5 March 2018. 